\title{
Open source software movement in the French central and local government: a retrospective and prospective exploratory study
}

\author{
Robert Deller* \\ University of Maryland/University College, \\ Institute of Government Business Services, USA \\ E-mail: bdeller@IGBS.org \\ ${ }^{*}$ Corresponding author
}

\section{Veronique Guilloux}

Master International Management, Université Paris 12,

61 av du général de gaulle, 94010 Créteil cedex, France

E-mail: veronique.guilloux@univ-paris12.fr

\begin{abstract}
As one of Europe's leaders in modernising government through the use of Information and Communication Technologies (ICTs), France offers an opportunity to investigate how the use of Open Source software contributes to the process of improving government performance. This paper examines the extent to which the French government accepts Open Source solutions as part of its use of ICT to support e-democracy through government operations. This study bases its investigation on interviews of more than 100 program and ICT officials responsible for running or supporting government programs in France.
\end{abstract}

Keywords: open source software; government modernisation; e-democracy; French government.

Reference to this paper should be made as follows: Deller, R. and Guilloux, V. (2008) 'Open source software movement in the French central and local government: a retrospective and prospective exploratory study', Int. J. Electronic Democracy, Vol. 1, No. 1, pp.1-13.

Biographical notes: Robert Deller's distinguished career involves senior government ICT and international e-government research - educational and journalistic. He analyses e-government best practices. His teaching addresses policies and implementation of internet-based solutions for government managers. He supports conference and workshop programs on e-government implementation, focusing on organisational benefits and liabilities. He provides ICT expertise for various international government organisations. Currently, he is Research Associate at Politech Institute, a European Center of Political Technologies located in Brussels, and develops consultancy through Markess International for applications of e-government and technology innovation. 
Veronique Guilloux is a French Assistant Professor. She is involved in the international management Master of Paris XII University. She has written several academic articles on open source. She is member of Acube Community, which is a French government open source project.

\section{Introduction}

An Open Source product is a computer software whose source code is available under a license (or arrangement such as the public domain) that permits users to use, change, and improve the software, and to redistribute it in modified or unmodified form. It is often developed in a public, collaborative manner. Many European national governments are experiencing benefits from programs based on Open Source solutions (http://www.epractice.eu/).

The government of France was chosen for this study because of an aggressive program in place in that country to encourage the use of Open Source solutions. Several initiatives taken by French government officials are key to understanding the role of Open Source solutions in this sector. In what had been misconstrued initially as a limitation against the use of Open Source solutions, the government introduced in June 2005 a copyright restriction bill, known as DADVDSI (droit d'auteur et droits voisins dans la société de l'information). Its principal focus was to protect the rights of authors to freely distribute their free or Open Source solutions.

France also took the initiative to evaluate how it could improve development and distribution of free software products. Licenses for free software use already exist, but they are mostly written in English, with inherent bias toward the US legal system, a system based on different legal assumptions than in France. Nevertheless, licensing systems should be compatible with the Free Software Foundation Inc.'s GNU General Public License (GPL). A new license, known as CeCILL, is intended to make free software more compatible with French law in two areas where it differs significantly from US law: copyright and product liability. According to an unidentified government official, all major ICT vendors in France support the initiative and are contributing to the development of open source products.

Since 2006, France has operated an Open Source centre of excellence. Thierry Breton, French Minister of the Economy, Finance and Industry at that time, identified two purposes for the centre. One was to promote availability of Open Source solutions; the other was to encourage French government use of Open Source solutions. In the process, a goal of the centre is a healthy and profitable open-source software industry. France's central government supports its modernisation through a Forge program http://admisource.gouv.fr/ tied with the Adele project (http://synergies.modernisation. gouv.fr/). France's local governments are also developing open source Forge with Adullact (http://www.adullact.org/). The European e-government observatory in providing enhanced public access to information about its imperatives lists recent French government activities related to Open Source (http://www.epractice.eu/). 


\section{Methodology}

The analysis performed for this paper is based on primary data collected from government officials involved in the use of Open Source solutions. In the absence of the existing analysis on this type of data, an empirical study represents the most reasonable basis for investigation. The fundamental questions addressed in the analysis were taken from published literature addressing Open Source use and practice of electronic government (e-government) in modernisation activities to improve services to citizens.

\subsection{Open source and e-government literature review}

Several papers or books analyse e-government (Perri, 2001; Bovaird, 2003; Heeks, 2005; Yildiz, 2007), but few academic articles could be found concerning a connection between Free and Open Source Solutions (FOSS) and government. Cook and Horobin (2006) reveal that governments of developing countries are at least aware of FOSS and wish to foster its use. Evans and Reddy (2003) describe how the open-source movement produces and distributes software and examines whether there is a significant market failure that would justify such intervention in the software industry. Even in the case of market failure, Hahn's book (2003) asks the question, "Should the government intervene in open source on its behalf?". A sceptical view of government's role in supporting FOSS is represented by Berry and Moss (2006) who show that an analysis of official discourse and government policy for non-proprietary software suggests that its introduction into government would bring more 'politics as usual' rather than democratisation. Representing a more positive view, Lee (2006) reports that some governments have actually begun to procure FOSS, whereas others have channelled public funds to large-scale FOSS projects. The most fundamental argument of the study is that in lending its support to FOSS, the difference between a government user and a business user is that the government should take into account society's long-term interests. Regarding access to FOSS, Hemphill (2005) shows that for governments the most effective and efficient procurement decisions would result from an encouragement of neutral standards, open competition for research funding of software development, and non-discrimination in computer software procurement policies.

While most literature focuses on national or central governments, Edminston (2003) presents a self-contained yet comprehensive discussion of the prospects of state and local e-government, the status of its development across the states and local communities, and the difficult challenges faced in making it a reality. Benamou (2005) explains that while e-government services have rapidly developed at national levels in most European countries, local governments are quite slow in moving online.

The interest of this paper is that the study analyses figures at two levels: local and central French government. Its value is that it serves to augment academic literature; otherwise, very weak concerning this dual government perspective. Considering that most interactions between government and citizens go through local governments, this situation is damaging the perception of e-government usefulness for citizens. Applications for FOSS in local government levels could enhance delivery of services to citizens, and thereby could improve an e-democracy practice. 


\subsection{Sample presentation}

A ready database of interviews was available from a leading French market research company targeting modernisation of industry and government. Participants in the interview process responded voluntarily to a questionnaire distributed over the internet to more than 5000 French government officials during a two-week period in April 2007. The response of 107 government officials represents a $2 \%$ response rate. There was no follow-up, so the response is considered in line with what can be expected from voluntary internet-based questionnaires. The sample of 107 respondents is broken out by central and local officials, as shown in Table 1. Officials from central government include ministers and senior program officials with various functional responsibilities and program focuses. Local governments include cities, towns, inter-community organisations and regional governments. The distribution of government workers between central and local governments in France is approximately equal at 1.5 million, not accounting for educators (http://www.fonction-publique.gouv.fr/article988.html). It is worth noting that while the number of respondents represented in this study is lower for central government, the budget dedicated by central government to Open Source is higher than for local governments. The ratio of available budget for Open Source platforms when compared with total budget for IT is reported for 2006 at $14 \%$ in the central government when compared with $7 \%$ for local government. This imbalance accentuates the lack of attention at local government levels to the use of FOSS.

Table 1 Respondents by government level

\begin{tabular}{lc}
\hline Government level & Number of respondents \\
\hline Central & 17 \\
Local & 90 \\
\hline
\end{tabular}

Respondents comprise different organisational responsibilities, as shown in Table 2. All respondents occupy decision-making or decision-supporting roles. They were also self-qualified to represent the interests of their respective organisations.

Table 2 Respondents by organisational responsibility

\begin{tabular}{lc}
\hline Function represented & Number of respondents \\
\hline Organisational director or deputy & 26 \\
Administrative manager & 35 \\
Project or program manager & 31 \\
Other & 15 \\
Total & 107 \\
\hline
\end{tabular}

Two organisation functions are important when considering the use of Open Source solutions. One function provides Information and Communication Technologies (ICTs) support, typically where systems are built and managed. The other function is responsible for program operations supported by Open Source solutions. Table 3 shows the distribution of respondents across these two organisational functions. The higher proportion of ICT support to program officials is not representative of government 
officials but even with bias, attaining informed opinions regarding Open Source solutions is helpful in understanding the role of Open Source solutions in government.

Table 3 Respondents by organisational function

\begin{tabular}{lc}
\hline Organisational function & Number of respondents \\
\hline ICT support & 85 \\
Program & 22 \\
\hline
\end{tabular}

\section{The data analysis}

The set of data used for analysis in this study represents both motivations towards use (or non-use) of Open Source software and experiences from actual usage.

\subsection{Motivation for use or non-use}

Most respondents in this study reported that they had already begun transforming systems and building new ones through the use of Open Source solutions. As shown in Table 4, by the year 2009, all centrally located government officials responding expect to have Open Source solutions operational. Local officials are not far behind with $81 \%$ indicating Open Source solution use by 2009. Although the data do not provide identification of degree to which an organisation may be totally committed to Open Source solutions, we get an idea of penetration of Open Source as an element in support to programs.

Table 4 Use of Open Source solutions

\begin{tabular}{lcc}
\hline & Percentage of central & Percentage of local \\
\hline Already have & 94 & 68 \\
By 2009 & 100 & 81 \\
\hline
\end{tabular}

\subsubsection{Motivations towards use of Open Source solutions}

To understand what motivates the use of - or decisions not to use - Open Source solutions, respondents were asked to provide their respective rationales, essentially to rank the principal reasons they had chosen or are choosing to use Open Source solutions. In the resulting rankings shown in Table 5, the cost of site licenses required for proprietary alternatives appears to be the leading driver in moving to Open Source solutions for 55 of the 83 respondents who provided reasons.

Table 5 Motivation towards use of Open Source solutions

\begin{tabular}{lc}
\hline Reasons cited for Open Source solutions & Percentage of respondents $(n=83)$ \\
\hline Lower cost of site licenses & 66 \\
Autonomy and independence & 47 \\
Performance (interoperability, standardisation, flexibility) & 37 \\
Value of collaboration and choice of supplier & 13 \\
All others & 17 \\
\hline
\end{tabular}




\subsubsection{No motivation towards use of Open Source solutions}

Of 14 local government respondents who indicated no intent to use Open Source solutions by 2009, 12 provided reasons for this lack of intent. Cultural prohibitions appear the dominant reason, as shown in Table 6. It may be significant that only six of the responses (lines 3-5) identify anticipated problems with the functionality of Open Source solutions rather than circumstantial issues (such as culture and no sense of need) that may relate to their respective environments. A relatively high percentage of none interest relates to negative attitudes towards Open Source solutions rather than functional uncertainty, in general.

Table 6 Reasons given for unanticipated use of Open Source solutions

\begin{tabular}{lc}
\hline Reasons for no anticipated use & No. of responses \\
\hline Cultural prohibitions & 6 \\
Don't feel the need & 3 \\
No internal competence & 3 \\
Not compatible with existing solutions (hardware and software) & 2 \\
Maintenance concerns & 1 \\
Legal issues & 1 \\
No time to investigate & 1 \\
Total respondents $=12$ & \\
\hline
\end{tabular}

The same respondents were asked under what conditions they would reconsider interest in Open Source solutions. It appears from these responses that even with a negative attitude (cultural) towards Open Source solutions, altered circumstances might be justification for reconsideration. Only a few indicated a need for cultural change, perhaps suggesting that cultural problems originated elsewhere in the organisation.

Help from third-party organisations for development, implementation, operations or maintenance were among the issues cited as needed for re-evaluation of interest.

\subsection{Usage of Open Source solutions}

To understand how Open Source solutions are currently operated, usage was divided into the four categories shown in Table 7. Only 87 of the 90 respondents who stated Open Source solutions would be running by 2009 identified specific usage for their Open Source solutions. Understandably, multiple usages were reported by the respondents.

Table 7 Use of Open Source solutions by major categories

\begin{tabular}{lcccc}
\hline & \multicolumn{2}{c}{ Central government $(n=17)$} & \multicolumn{2}{c}{ Local government $(n=70)$} \\
\cline { 2 - 5 } & Already used $(\%)$ & By 2009 $(\%)$ & Already used $(\%)$ & By 2009 $(\%)$ \\
\hline Applications & 88 & 100 & 64 & 87 \\
Servers & 88 & 94 & 70 & 80 \\
Utilities & 59 & 65 & 41 & 51 \\
Network security & 47 & 65 & 50 & 56 \\
\hline
\end{tabular}




\subsubsection{Application usage}

Based on the responses shown in Table 7, by 2009 most usages of Open Source solutions will be found in applications and in servers, with central government (100\%) more than local government $(87 \%)$ focused on applications. In either government level, use of Open Source solutions will grow most dramatically in application use. Utilities and network/security usage is represented by the lowest growth rate. With almost half the respondents indicating uncertainly or no interest, these categories represent areas where officials need the most convincing, presumably through external support.

A closer look at application usage in Table 8 shows ten different application areas identified by the respondents, from both central and local governments.

Table 8 Distribution of Open Source use across application areas

\begin{tabular}{lcccc}
\hline & \multicolumn{2}{c}{ Central government $(n=17)$} & \multicolumn{2}{c}{ Local government $(n=70)$} \\
\cline { 2 - 5 } & Already $(\%)$ & By $2009(\%)$ & Already $(\%)$ & By 2009 $(\%)$ \\
\hline Content mgt & 82 & 88 & 61 & 83 \\
Database mgt & 76 & 82 & 57 & 71 \\
Office systems & 59 & 76 & 43 & 64 \\
Portal & 59 & 71 & 43 & 63 \\
Collaborative & 59 & 71 & 36 & 61 \\
Messaging & 29 & 59 & 31 & 43 \\
Graphic design & 35 & 53 & 26 & 41 \\
Groupware & 29 & 47 & 20 & 39 \\
System admin & 35 & 47 & 37 & 49 \\
Supervision util. & 47 & 59 & 36 & 47 \\
\hline
\end{tabular}

Content management and database management systems appear to be the most popular intended uses for Open Source solutions, both for central and local governments. The lower interest in messaging, graphic design, groupware and supervisory applications may be due to the packaged proprietary nature of such applications.

\subsubsection{Network security}

With network security systems lagging behind other usages for Open Source solutions (refer back to Table 7), different elements of security were investigated to see if any were significant. Table 9 shows a distribution of Open Source solutions for the different security solutions identified. From this distribution, there appears to be uncertainty in what is appropriate for Open Source solutions, with directory services slightly more popular overall, but still with less than half the respondents planning such use. It is interesting to note a difference between central (53\%) and local (39\%) government officials on the appropriateness of Open Source solutions to provide directory service support. Lower usage in electronic signatures and key management may also be due to the proprietary commercial availability of such tools. Although the categories appear to represent the areas of greatest growth, the segment is small and percentages may not be sustained across a larger denominator. 
Table 9 Distribution of Open Source solutions across various security applications

\begin{tabular}{lcccc}
\hline & \multicolumn{2}{c}{ Central government $(n=17)$} & \multicolumn{2}{c}{ Local government $(n=70)$} \\
\cline { 2 - 5 } & Already $(\%)$ & By $2009(\%)$ & Already $(\%)$ & By 2009 $(\%)$ \\
\hline Directory services & 29 & 53 & 31 & 39 \\
Firewall & 24 & 24 & 31 & 43 \\
Virus protection & 24 & 24 & 15 & 40 \\
Electronic Sign & 12 & 29 & 7 & 29 \\
Key mgt & 0 & 24 & 10 & 24 \\
\hline
\end{tabular}

\subsubsection{Critical applications}

Based on the data represented in Table 7, the area with the highest interest for government executives was applications. When respondents were asked about applications they considered critical, they responded with less certainty that Open Source solutions were appropriate, with less than half (43\%) indicating favourability towards use of Open Source solutions. As shown in Table 10, central government officials reflected somewhat more confidence (59\%) than local governments $(39 \%)$ in areas where risk occurs.

Table 10 Distribution of Open Source solutions in critical applications.

\begin{tabular}{lcc}
\hline & Already $(\%)$ & By 2009 $(\%)$ \\
\hline Central $(n=17)$ & 53 & 59 \\
Local $(n=70)$ & 24 & 39 \\
\hline
\end{tabular}

\subsubsection{External services}

Respondents were asked to identify the extent to which they depended on external services for assistance in operating Open Source systems or moving to Open Source solutions. Table 11 identifies how respondents used or expected to use external sources. Multiple uses were identified.

Table 11 Extent to which respondents took advantage of external 'partners'

\begin{tabular}{lcc}
\hline & Central $(n=17)(\%)$ & $\operatorname{Local}(n=70)(\%)$ \\
\hline With external help & 88 & 94 \\
No external help & 12 & 6 \\
\hline
\end{tabular}

One interpretation of this data is that government organisations are not inclined to accept responsibilities for support to Open Source solutions.

Respondents were also asked to identify those critical environments in which they used or planned to use Open Source solutions. Table 12 shows those environments identified. Consistent with results shown in Table 8, respondents seem to accept Open Source solutions more readily for data handling (15 of 28) and document handling (10 of 28) environments. The 'all other' category includes workflow, data warehousing, and access control. 
Table 12 Critical environments identified for Open Source solutions

\begin{tabular}{lc}
\hline Environments identified & Respondents $(n=28)$ \\
\hline Databases & 15 \\
Digitising and handling on-line documents & 10 \\
Program applications & 3 \\
Internet/intranet portals & 2 \\
Accounting and finance & 2 \\
Scheduling & 2 \\
Geographic information systems & 2 \\
All other & 4 \\
\hline
\end{tabular}

\subsubsection{Operating environments}

Generally speaking, operating environments consist of three major components:

- central processing environments

- application servers that process individual elements of an operating environment, such as databases and mail servers

- individual workstations.

Each of these components can be regarded critical in terms of reliability and security of computer operations. Respondents were asked to what extent Open Source solutions are and will be used for operating in each of these three environments.

Table 13 shows expected changes from 2007 to 2009 for Open Source solutions in different processing environments. Although Open Source solutions represent small proportional use in central processing environments for central (15\%) and local (11\%) government in 2007, the doubling of expected use by 2009 is dramatic.

Table 13 Expected use of Open Source solutions

\begin{tabular}{lcccccc}
\hline & \multicolumn{2}{c}{$\begin{array}{c}\text { For central processing } \\
\text { environments }\end{array}$} & For application servers & For workstations \\
\cline { 2 - 7 }$(n=77)$ & $2007(\%)$ & By 2009 (\%) & $2007(\%)$ & By 2009 $(\%)$ & $2007(\%)$ & By 2009 $(\%)$ \\
\hline Central & 15 & 27 & 25 & 39 & 4 & 20 \\
Local & 11 & 22 & 15 & 29 & 6 & 19 \\
\hline
\end{tabular}

Application servers constitute the second listed segment of the processing environment. Respondents were asked to what extent application servers are or will be running under Open Source solutions. The increase to more than $30 \%$ of environments shown in Table 13 is not as dramatic a growth rate as for workstation environments, but a growing rate of approximately doubling is impressive, although remaining at less than half of application server environments. Another reason for the lower growth rate for application servers is that the number of Open Source solutions already in place is nearly $20 \%$ for total government. 
Access to processing environments typically occurs through workstations, the third listed element of processing environments. Here, the numbers for expected use are lower, probably accounted for by a near monopoly on workstation operating environments by Microsoft and Sun Microcomputers. Nevertheless, the growth in usage appears more dramatic at four times the proportion for 2007 - approximately from $5 \%$ to $20 \%$.

\subsection{Model}

Based on the questionnaire analysis, a model was drawn and used in this paper. We have inserted an influence for European e-government even if it was not investigated in this study.

The following schema summarises the different variables. The Europe e-government has an indirect impact. As Bradier (2004) reminds us, there are several European priorities: organisational and semantic and technical interoperability, facilitating access, and need for good practices at the European level.

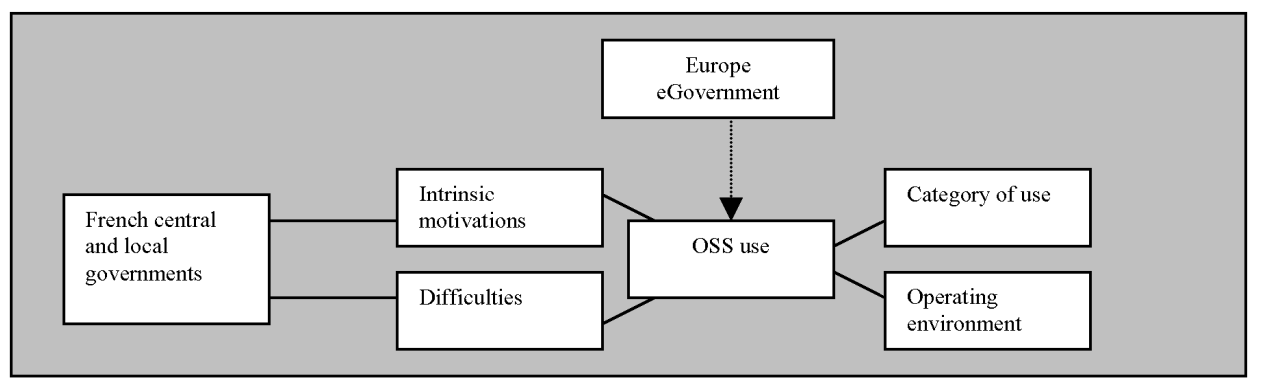

The results of this study show a real progression of Open Source usage and not just at a central level. Local government prospective figures are also promising. Several European projects like TERREGOV addressing the issue of interoperability of e-government services for local and regional governments (http://www.terregov. eupm.net/) could have stimulated this development.

\section{Conclusion}

In answer to the major question posed for this exercise, both central and local governments in France are already moving to Open Source solutions. In many environments, greater numbers of Open Source solutions are expected to be in place by 2009 , only an year away. Two major barriers to distribution of Open Source solutions appear to be accommodated. Anticipation of restricted distribution through copyrights and other protected uses for commercial products may have been taken care of by the CDADVDSI legislation. The other barrier, proprietary operating systems for workstations and other single-user computers are being replaced by Open Source systems in decisions taken by government's top management. Cultural barriers that existed are being reduced to only lack of experience in running environments based on Open Source solutions. 
Encouragement by French government officials through the centre of excellence should further increase interest and experience in Open Source solutions. With industry participation as well as government officials taking initiatives to move to Open Source solutions, a larger database of users should be available to share lessons and problem solutions. Third-party partnerships are of great interest to government officials, potentially improving levels of use and building a business base for industry.

With regard to support to e-Democracy practices, two messages can be drawn from the data. One is that government improvement in data quality through Open Source solutions seems imperative. At the local level, this would be even more critical as citizens tend to seek information support from local sources more readily than from central government sources (Edminston, 2003; Benamou, 2005). The fact that internet support does not rank high as a critical element may have a limiting value for e-Democracy since the internet is increasingly the medium used by citizens for access.

The results of this study are consistent with literature that describes an operating system environment in France rapidly changing to Open Source solutions. Even with a reasonably large current foundation of Open Source product users, French government officials seem eager to expand their use, expressing expectations in several areas: lower cost, freedom from proprietary dependencies for site licensing and system upgrades, and solution sharing through collaboration with other government centres.

Finally, this study provides a database against which future enquiry can be measured. The voluntary nature of responses could be due to difficulties with the subject, either from lack of experience or from lack of understanding of the Open Source technologies. With expanded use of Open Source solutions, experience as a factor in non-responsiveness to enquiry may be reduced. Consequently, more information should become available for researchers on the question of Open Source use.

\section{Perspective and future research}

One area that could benefit from more investigation is budget size, or anticipated spending for Open Source solutions. Current spending sizes can be misleading since some motivation towards Open Source solutions is due to cost reduction rather than for functional improvements. Current ICT budgets that show no increase could be due to an anticipation of less costly investments in Open Source solutions.

Running a similar enquiry in 2009 would be helpful to see what progress in moving to open operating environments may have been made, comparing it with expectations resulting from the data supporting this study. A larger database of respondents could result if follow-up were included in the sampling process. If a large enough sample could be drawn, an analysis of variance could be conducted to see how representative the samples are to the population of all French government officials.

In 2009, if projections found in this study hold, a larger database of Open Source product users could generate a more mature attitude towards Open Source solutions. Reasons for and against such use would constitute more than conjecture, possibly overcoming many cultural uncertainties. With more commercial Open Source solutions available in the marketplace, solutions for under-represented applications (such as network security) that are not currently of interest to government officials, could change attitudes and increase usage. 
Additionally, similar sets of data might be collected from other European governments that are aggressively pursuing modernisation and are entertaining value for Open Source solutions.

Analyses of private sector data could be compared with the data used in this study, and with future data collection as was suggested for governments. Progress cannot be made in Open Source product use without help from industry, either as developers of products or as third-party support to government users. A growing relationship between the two entities can be anticipated.

An examination of citizen satisfaction in response to e-Democracy promises can also be performed. Perri (2001) underlined that e-service delivery, e-democracy, and e-governance as different parts of e-government are interconnected. This study did not examine this set of data, but it would be invaluable to determine in the final analysis if e-democracy is a realisable promise of government. The data reveals that e-government is nearer French citizens (local e-government). OSS is an opportunity to develop it with reasonable budget and preserving interoperabililty. Local e-governance should now be analysed in a normative way proving that e-democracy is underway (Calista and Melitski, 2007).

\section{Acknowledgement}

Authors thank Markess International for making available for this paper data collected in its recent investigation of open source systems in the French government.

\section{References}

Benamou, N. (2005) 'Bringing eGovernment interoperability to local governments in Europe', European Review of Political Technologies, Vol. 3, pp.1-9.

Berry, D. and Moss, G. (2006) 'Free and open source software: opening and democratising e-government's black box', Information Policy, Vol. 11, pp.21-34.

Bovaird, T. (2003) 'E-government and e-governance: organisational implications, options and dilemmas', Public Policy and Administration, Vol. 18, No. 2, pp.37-56.

Bradier, A. (2004) 'Le gouvernement électronique: une priorité européenne', Revue française d'administration publique, Vol. 110, pp.337-347.

Calista, D.J. and Melitski, J. (2007) 'E-government and e-governance: converging constructs of public sector information and communications', Public Administration Quarterly, Spring, pp. 87-120.

Cook, I. and Horobin, G. (2006) 'Implementing eGovernment without promoting dependence: open source software in developing countries in Southeast Asia', Public Administration and Development, Vol. 26, No. 4, pp.279-289.

Edminston, K. (2003) State and local e-government: prospect and challenges, American Review of Public Administration, Vol. 33, No. 1, pp.20-45.

Evans, D.S. and Reddy, B.J. (2003) 'Government preferences for promoting open-source software: a solution in search of a problem', 9 Mich. Telecomm. Tech. L. Rev., Vol. 313, Available at http://www.mttlr.org/volnine/evans.pdf

Hahn, R. (Ed.) (2003) Government Policy toward Open Source Software, American Enterprise Institute Press.

Heeks, R. (2005) Implementing and Managing eGovernment: An International Text, Sage Publications, London. 
Open source software movement in the French central and local government 13

Hemphill, T. (2005) 'Government technology acquisition policy: the case of proprietary versus open source', Bulletin of Science Technology Society, Vol. 25, pp.484-490.

Lee, J-A. (2006) 'Government policy toward open source software: the puzzles of neutrality and competition, knowledge', Technology, and Policy, Winter 2006, Vol. 18, No. 4, pp.113-141.

Perri (2001) 'E-governance: Do digital aids make a difference in policy making', in Prins, J.E.J. (Ed.): Designing E-government: On the Crossroads of Technological Innovation and Institutional Change, Kluwer Law International, The Hague, pp.7-27.

Yildiz, M. (2007) 'E-government research: reviewing the literature, limitations, and ways forward', Government Information Quarterly, Vol. 24, No. 3, July, pp.646-665. 